\title{
IMPLEMENTATION OF ACTIVE TEACHING METHODS AND EMERGING TOPICS IN PHOTOGRAMMETRY AND REMOTE SENSING SUBJECTS
}

\author{
M. Kosmatin Fras ${ }^{\text {a, } *, \text { D. Grigillo }}{ }^{\text {a }}$ \\ ${ }^{a}$ University of Ljubljana, Faculty of Civil and Geodetic Engineering, Jamova cesta 2, 1000 Ljubljana, Slovenia - (mojca.kosmatin- \\ fras, dejan.grigillo)@fgg.uni-lj.si
}

Commission WG VI/V

KEY WORDS: University Education, Active Teaching Methods, Photogrammetry, Remote Sensing, Lectures, Practical Exercises.

\begin{abstract}
:
Fast technological developments in photogrammetry and remote sensing areas demand quick and steady changes in the education programme and its realization. The university teachers and assistants are faced with ensuring the learning materials, data and software for practical lessons, as well as project proposals for student's team work and bachelor or master thesis. In this paper the emerging topics that already have a considerable impact in the practice are treated mostly from the educational aspect. These relatively new topics that are considered in this paper are unmanned aerial systems for spatial data collection, terrestrial and aerial laser scanning, mobile mapping systems, and novelties in satellite remote sensing. The focus is given to practical implementation of these topics into the teaching and learning programme of Geodesy and Geoinformation at the University of Ljubljana, Faculty of Civil and Geodetic Engineering, and experiences gained by the authors so far. Together with the technological advances, the teaching approaches must be modernized as well. Classical approaches of teaching, where a lecturer gives lecture ex cathedra and students are only listeners, are not effective enough. The didactics science of teaching has developed and proved in the practice many useful approaches that can better motivate students for more active learning. We can use different methods of team work like pro et contra debate, buzzing groups, press conference, moderated discussion etc. An experimental study on active teaching methods in the class of students of the Master programme of Geodesy and Geoinformation has been made and the results are presented. After using some new teaching methods in the class, the students were asked to answer two types of a questionnaire. First questionnaire was the standard form developed by Noel Entwistle, an educational psychologist who developed the Approaches to Studying Inventory (ASI) for identifying deep and surface approaches to learning. The second questionnaire was developed for our purpose to get the feedback from students on active teaching and learning methods. Although this investigation has been done only for one class of master programme students, the results are encouraging and we could extract some recommendations for the future.
\end{abstract}

\section{INTRODUCTION}

\subsection{Background}

With the increased availability of data sources collected with remote sensing and photogrammetric technologies the application of imagery is now ubiquitous, playing an important role in many aspects of life and work today (Chen et al., 2015). Due to these steady and fast technological developments, Universities that are educating in these professional fields must adapt the educational programmes as currently as possible. On the other hand the time devoted for lectures and practical exercises in the curriculum is limited, thus university teachers and assistants should apply improved teaching methods to incorporate new topics.

The aim of this paper is two-fold: to present the emerging topics in photogrammetry and remote sensing from educational aspects and giving some practical examples, as well as present some active teaching methods that can improve the efficiency of lectures in a class. The examples and experiences gained by the authors so far and presented in this paper are referring to the teaching and learning programme of Geodesy and
Geoinformation at the University of Ljubljana, Faculty of Civil and Geodetic Engineering.

In the framework of higher education programmes renovation according to the principles of Bologna process new study programmes in the field of surveying and geodesy have been prepared at the University of Ljubljana, Faculty of Civil and Geodetic Engineering (UL FGG), in 2007 and 2008 (Petrovič et al., 2008). Programmes of that time have been replaced with five new programmes at three higher education levels as proposed by Bologna Declaration. At $1^{\text {st }}$ level: University Bachelor degree study programme Geodesy and Geoinformatics (BA-GG) and Professional Bachelor degree programme Technical Real Estate Management (BA-TREM). At $2^{\text {nd }}$ level: Master degree programme Geodesy and Geoinformatics (MAGG) and interdisciplinary programme Spatial Planning (MASP). At $3^{\text {rd }}$ level Doctoral study programme Built Environment with three study orientations, among which two orientations are Geodesy, and Spatial Planning and Land management. In this paper we are considering only $1^{\text {st }}$ and $2^{\text {nd }}$ level programmes.

\footnotetext{
* Corresponding author
} 


\subsection{Photogrammetry and Remote Sensing Subjects in the Curriculum}

The curriculum of Bachelor and Master programmes in the field of surveying and geodesy at the University of Ljubljana, Faculty of Civil and Geodetic Engineering, contains different subjects of photogrammetry and remote sensing. The list of these subjects is presented in Table 1 .

\begin{tabular}{|l|l|l|c|}
\hline Programme & \multicolumn{1}{|c|}{ Subject } & Status & $\begin{array}{c}\text { lectures/exercises (hrs.) } \\
\text { ECTS }\end{array}$ \\
\hline BA-GG & Photogrammetry 1 & obligatory & $30 / 45$ \\
& & & 5 \\
\cline { 2 - 4 } & Remote Sensing 1 & obligatory & $30 / 30$ \\
& & & 4 \\
\hline BA-TREM & Remote Sensing and & obligatory & $45 / 60$ \\
& Photogrammetry & & 7 \\
\cline { 2 - 4 } & Topographic & elective & $30 / 30$ \\
& Photogrammetry & & 4 \\
\hline MA-GG & Remote Sensing and & obligatory & $60 / 60$ \\
& Photogrammetry 2 & & 8 \\
\cline { 2 - 4 } & Close Range & elective & $15 / 30$ \\
& Photogrammetry & & 3 \\
\hline MA-SP & Remote Sensing for & elective & $30 / 15$ \\
& Spatial Planning & & 3 \\
\hline
\end{tabular}

Table 1: Photogrammetry and Remote Sensing subjects in the curriculum of University of Ljubljana, Faculty of Civil and Geodetic Engineering

In addition to these subjects, at $2^{\text {nd }}$ level of the programme Environmental Civil Engineering, the subject Remote Sensing in Environmental Civil Engineering is taught as obligatory subject, with 30 hours of lecture and 30 hours of practical exercises (4 ECTS). This subject introduces the elementary terms and methods of remote sensing, with the emphasis on specific applications and use of topographic data (e.g. lidar point clouds, digital terrain models, orthophoto) for management of waters.

In all the subjects in the $1^{\text {st }}$ level the basics of remote sensing and photogrammetry are thought, thus there are no particular difficulties (use of standard equipment, variety of learning materials etc.) in theirs realization. The most comprehensive and from teaching aspect the most complex subject is Remote Sensing and Photogrammetry 2 at Master degree programme Geodesy and Geoinformatics. In this subject many new technologies are treated and a lot of special equipment and software is needed for practical exercises. There is around $30-$ 35 students in a class every year. In addition we also have a few students from the study of Geography (Faculty of Arts) that are attending this subject as elective. They find this subject attractive with many new topics they cannot hear or practice at their programme. Some exchange Erasmus programme students select this subject as well. As in this paper we are describing practical examples in the case of this subject, we present here the syllabus in more details:

Camera calibration methods

Advanced methods of aerial triangulation (AT): automated AT, GNSS supported AT, integrated sensor orientation

Direct sensors orientation

- Photogrammetric acquisition of topographic data for building up topographic data sets

- Quality assurance and quality control in photogrammetric projects

Planning of photogrammetric project

- Current satellite systems for data collection of Earth's surface
Aerial laser scanning: physical characteristics of laser beam, system components, main phases of data collection and processing, products and their use Generation of digital terrain models from the remote sensing and photogrammetric sources

Object based classification and its applications

Mobile mapping systems: characteristics,

components, workflow, products and their use

Terrestrial laser scanning connected with

photogrammetric applications

Selected case studies from the practice

The objectives and competences are that students extend and deepen their knowledge from the $1^{\text {st }}$ study level in order to be able to manage complex projects for data collection with different methods of remote sensing and photogrammetry. Thus, we expect that students learn to connect theory and practice, they are able to understand modern technologies of remote sensing and photogrammetric processes, as well as they are aware of steady technological advancement.

For organizing lectures, practical exercises, learning materials, seminar tasks and other activities, as well as for communication with students, the faculty web classroom is available (organized in Moodle). Also the Digital Repository UL FGG named DRUGG (Figure 1) is available for students and everyone from the web (http://drugg.fgg.uni-lj.si/), where bachelor, master and doctoral thesis, as well as other useful materials and papers produced by the faculty staff can be downloaded (Koler-Povh et al., 2014).

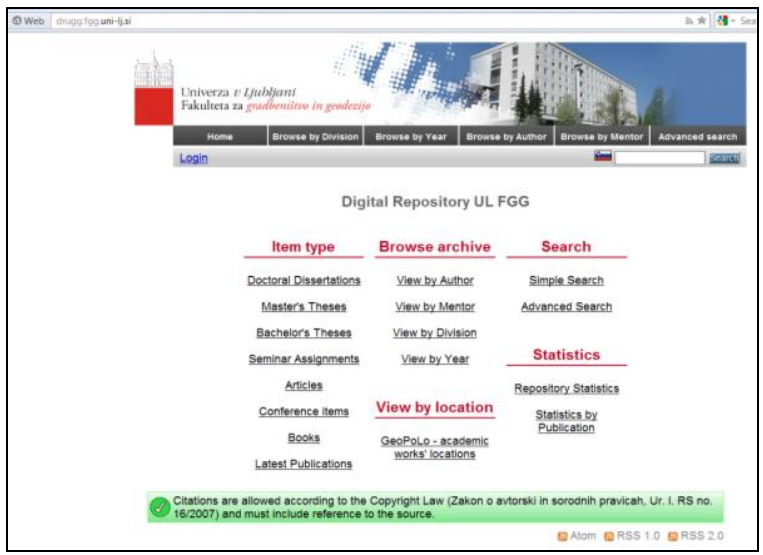

Figure 1: Entry web page of Digital Repository UL FGG

Practical exercises are carried out in computer rooms. For remote sensing and photogrammetry subjects we use computer room equipped with dedicated software tools, e.g. for 3D stereo data collecting (Figure 2), processing of images from UAS, processing of lidar data etc.

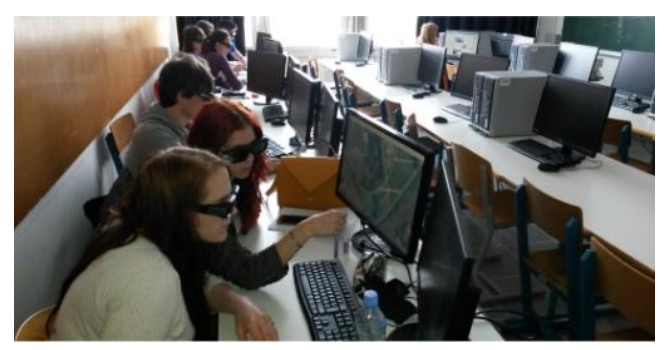

Figure 2: Students running practical exercises in computer room 


\section{IMPLEMENTATION OF EMERGING TOPICS INTO TEACHING PRACTICE}

The university teachers and assistants are nowadays burdened with ensuring the learning materials, instructions for practical lessons, as well as project proposals for student's team work and bachelor or master thesis. For teaching purposes in remote sensing and photogrammetry, especially for practical exercises, we need quite a lot of different dedicated equipment (e.g. terrestrial laser scanner, unmanned aerial system), software (aerial triangulation, 3D stereoscopic data acquisition, processing of UAS images blocks, TLS data processing, 3D data modelling etc.), capable computers, appropriate and organized data etc.

As the financial resources are limited, we are not able to purchase all the newest items, so we have to search for different solutions. To our experience, one of the most effective approaches to augment the range of our capacities is establishing good connections and cooperation with private companies and other institutions. In Slovenia there are companies that have good, special equipment or even they develop their own systems and software. We can get data for practical exercises or for graduation thesis, or get academic discounts for software. Sometimes we organize visits to companies so that students can see the production environment, or the professional colleagues give lectures about interesting projects. Another option is to use open source and free source software for teaching purposes. However, this software is not always reliable, the instructions or tutorials might be weak thus we need to test the particular program before using it with students. In some cases, students develop the equipment of their own (unmanned aerial system described in chapter 2.1), or develop computer programs, for example program ORIS for close range application developed in university degree thesis (Balek, 2014). Fortunately, we can get the national spatial data for educational and research purposes for free (e.g. aerial images, national orthophoto, vector topographical data, national laser scanning data etc.)

Regarding the theoretical concepts, in order to efficiently use the scope of scheduled lectures, we can merge some topics and explain it in general. For example, when dealing with kinematic platforms carrying different sensor, general approach is the same. We have to calibrate the system: define level arms between GNSS, IMU, camera or laser scanner; define boresight alignment between IMU and laser scanner, define a common time frame and interpolate measured data as function of time (Kai-Wei et al., 2012). After introducing the general concept we can than just refer to it when talking about GNSS supported aerial triangulation or indirect sensor orientation, mobile mapping systems, unmanned aerial systems or aerial laser scanning.

In the subchapters (2.1-2.5) we explain in more details the particular topics and give some practical examples.

\subsection{Unmanned Aerial Systems}

In the recent years, small unmanned aerial systems (UAS) equipped with consumer-grade imaging sensors offer low-cost and automated production of point clouds, although usually limited to smaller terrain coverage. As already recommended by Al-Tahir (2015) and some other authors the geomatics engineering programs should incorporate UAS in their curriculum. Although this topic is not explicitly listed in our curriculum, we introduced it recently in lectures and practical exercises as it can be regarded also as a kind of aerial surveying or a mobile mapping system. Students are mostly attracted by this technology as they can take active part in all the steps of data collection and processing. In academic year 2013/2014, a group of enthusiastic students of our MA-GG programme has built its own quadrocopter named "FlyEye" for collecting spatial data from images (Figure 3 and Figure 4). Building an UAV from the scratch was a big challenge for the students to learn about this modern technology.
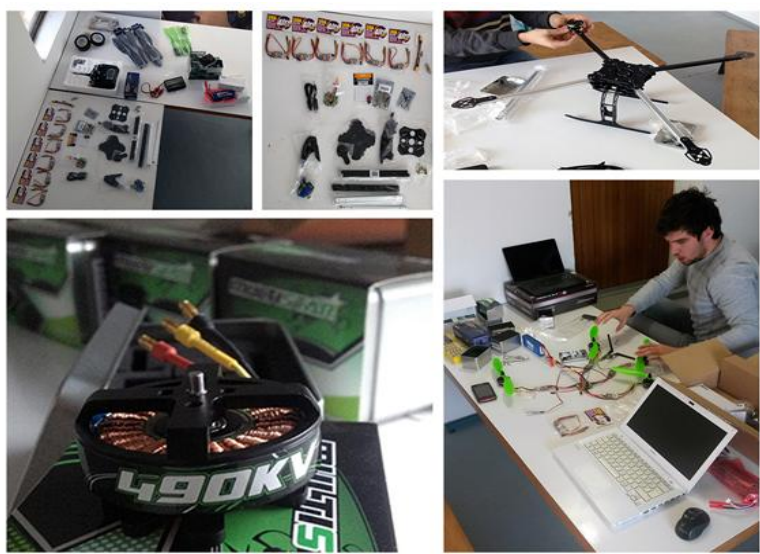

Figure 3: Building the quadrocopter by a group of student from the purchased components

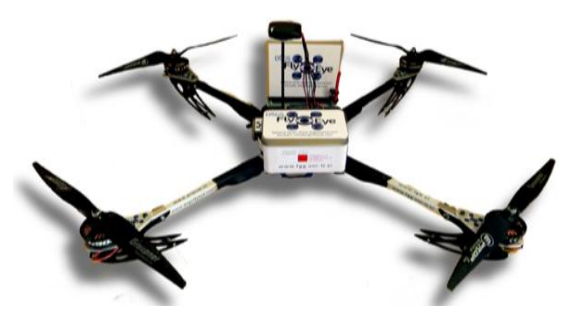

Figure 4: Built UAV - FlyEye

With the support of their professors and assistants from the faculty the students are testing the system in different projects (http://www.dsgsflyeye.com/) and the results are promising. Some presentations of the technology for the public have been organized and different media (TV, newspapers, internet media) reported on this. This UAS is now available for practical lessons and researches at our faculty.

In addition to the surveying equipment, we need software for image processing and generation of final products. Different commercial products are available in the global market for this purpose. However, we recently purchased multiple licenses of the software 3Dsurvey developed by Slovenian company Modri planet, that students can use for practical exercises in our computer room. This software is competitive to the existing globally promoted software and is being developing by engineers of geodesy that graduated from our faculty a few years ago. 3Dsurvey is the software for collecting and processing data from images for surveying land and built environment (http://www.3dsurvey.si/). The basic input for data acquisition are aerial images taken from the UAS, terrestrial images or combination of both. Image matching algorithms and photogrammetric bundle block adjustment are implemented to compute the image orientation parameters and point clouds of 
different density level from high to low (Peterman, 2015). Classification of point cloud to terrain points and other classes can be accomplished interactively or automatically. The software can then produce digital terrain model and orthophoto. Additionally, some applications are implemented, for example calculation of areas and volumes (Figure 5), measurement of distances, derivation of contour lines of chosen equidistance, automatic production of longitudinal and transverse profile plots at selected locations.

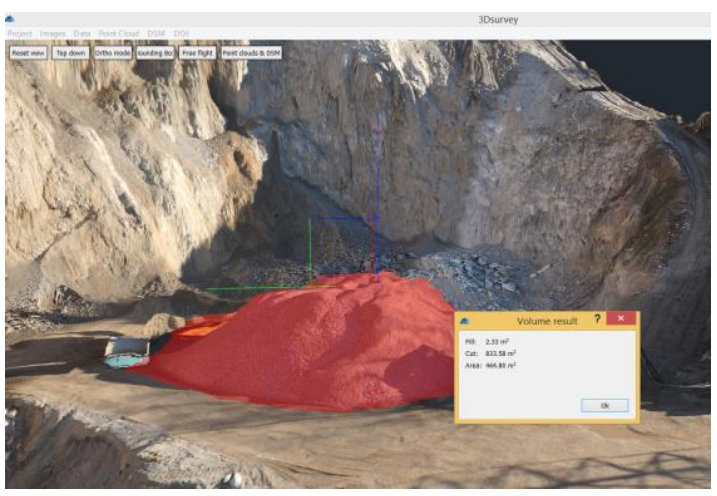

Figure 5: Calculation of volumes in software 3Dsurvey (Kosmatin Fras et al., 2015)

With practical exercises using this software our students can easily learn the complete production line.

\subsection{Terrestrial Laser Scanning}

In 2013 our faculty purchased a terrestrial laser scanner Riegl VZ-400, with very favourable support from the company Riegl in the means of academic discount, and additional licenses for RiSCAN PRO software free of charge. We implemented the equipment immediately into the practical exercises in two different subjects (Geodetic Measurement System, Remote Sensing and Photogrammetry 2; both in Master degree programme). The practical exercises were harmonized between the both subjects. In the course of the subject Geodetic Measurement Systems, terrestrial laser scanning and the process of scan registration is theoretically explained and accomplished in the practical exercises. In the case study students scanned a building near our faculty and carried out the registration step in Matlab. Tie points were signalised with spheres and point clouds were exported as ASCII files. The sphere centres were adjusted and were then used for the adjustment of transformations. Obtained transformation parameters were imported into RiSCAN PRO as SOP matrices. Geodetic network was also measured using GNSS and TPS to define control points for point cloud georeferencing. Data postprocessing was performed during exercises of the subject Remote Sensing and Photogrammetry 2. Georeferenced scans were used to produce 3D model of the building. Students employed different algorithms in RiSCAN PRO to create the model. RiSCAN PRO is designed to manage the whole project from data acquisition to data processing. Nevertheless, its main function is not 3D modelling, and production of 3D models demands a lot of manual work. Thus, in exercises we also examine different open source tools for 3D modelling of the pre-processed point clouds, such as MeshLab (Figure 6).
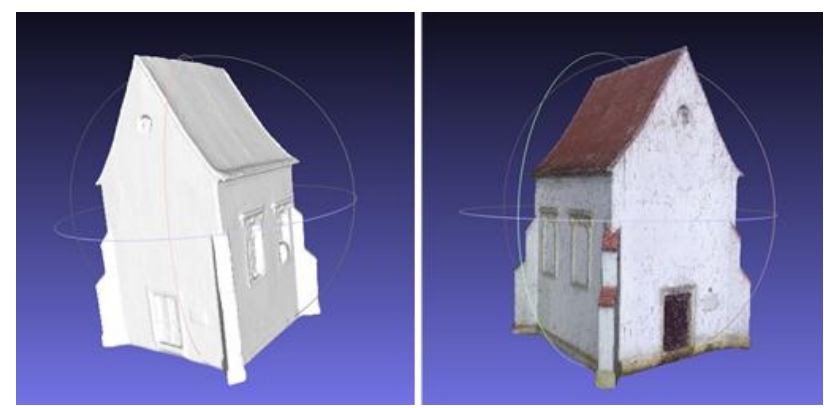

Figure 6: 3D modelling of a building in Meshlab

The students are also encouraged to produce their own basic modules for modelling steps, as for example segmentation of filtered point cloud using RANSAC (Figure 7).
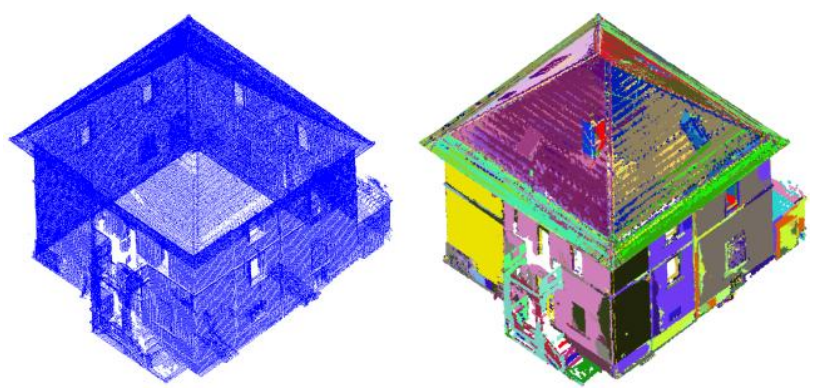

Figure 7: Segmentation of filtered point cloud with RANSAC

\subsection{Aerial Laser Scanning}

We cannot expect that the faculty will have its own equipment for aerial laser scanning (lidar) as this is very costly. However, it is important for students to learn the steps of processing lidar data. In 2011 begun a huge project Laser Scanning of Slovenia and has been completed in 2015 (Triglav et al., 2015). The data (georeferenced and classified point clouds, and digital terrain model - DTM1, interpolated in a grid cell with spatial resolution of $1 \mathrm{~m}$ ) is freely available. The project has been financed by Republic of Slovenia, the Ministry of Environment and Spatial Planning and accomplished in cooperation of Geodetic Institute of Slovenia, Flycom, and University of Maribor - Faculty of Electrical Engineering and Computer Science. The territory of the Republic of Slovenia has been divided into different scanning blocks (Figure 8). Most of the territory has been scanned with the density of 5 points $/ \mathrm{m}^{2}$ (first pulse), some areas of dense forest and mountains with 2 points $/ \mathrm{m}^{2}$, and a few endangered areas for floods and landslides with 10 points $/ \mathrm{m}^{2}$.

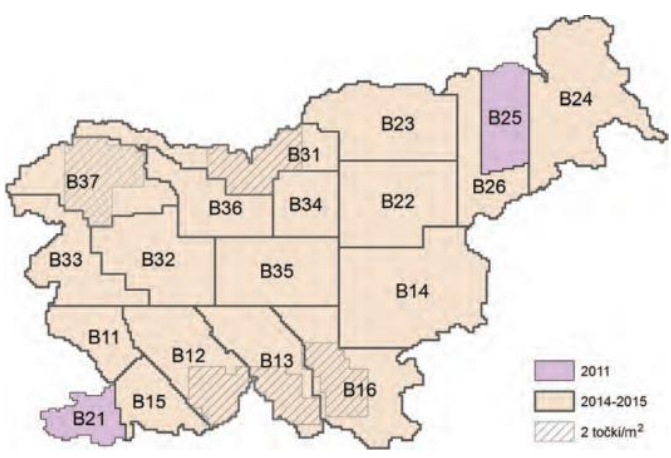

Figure 8: Republic of Slovenia divided into laser scanning blocks (figure adopted from Triglav et al., 2015) 
As soon as the data was available, we prepared some exercises for students based on this data. Students learn how to access the data and use it for different applications. With fusion of lidar data and infra-red orthophotos students produce building mask and detect changes in topographic databases as described in Grigillo et al. (2011). They also use lidar data to calculate watersheds and longitudinal profiles of torrential streams. From unclassified point clouds they produce their own DTMs and evaluate them by comparison to the national DTM1. The processing of the lidar data is carried out using free software, for example LAStools or Fusion, FugroViewer for data visualization, while further analyses are performed in ESRI's ArcGIS, which is provided by the University of Ljubljana.

\subsection{Mobile Mapping Systems}

Mobile mapping is an approach for compiling information on physical environment from a mobile vehicle. Mobile mapping system is typically composed of photographic, laser or any other remote sensing system, and position (GNSS) and navigation sensors (INS or IMU). All the devices must be synchronised in a common time frame and calibrated.

Our faculty has established good cooperation with the Slovenian company DFG Consulting (http://www.dfgcon.si/en/) which performs different highly professional and innovative projects in remote sensing and photogrammetry, GIS etc. Among many in-house developed software solutions they developed their own mobile mapping system WideoCar (Figure 9 - left), which is being continuously upgraded. The platform is a car and the system is equipped with two video cameras enabling stereo image data acquisition, spherical camera, position and orientation system (GNSS, INS and some other sensors), and optionally a terrestrial laser scanner.

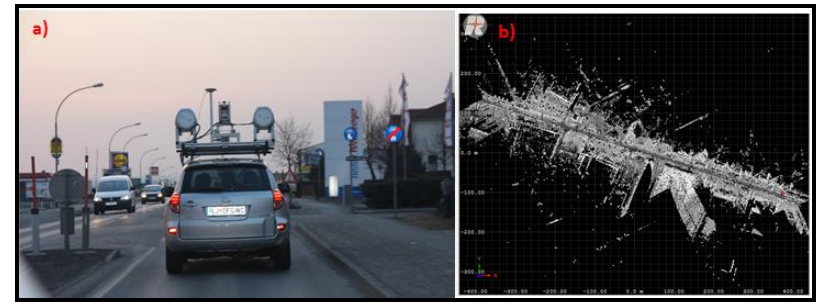

Figure 9: (a) Mobile mapping system (WideoCar) developed by Slovenian company DFG Consulting, (b) test point cloud for boresight alignment calibration (test site of Riegl company in Horn, Austria) (Kumar, 2013)

Some of our students are accomplishing their graduation thesis with the equipment and software in the company (calibration of video cameras in the mobile mapping system, automatization of relative orientation for the cameras in mobile mapping system etc.). One of the faculty awarded university graduation thesis was on realization and calibration of the in-house developed mobile laser system as an equivalent to commercially available and much more expensive systems (Kumar, 2013). A specialty of the tested mobile laser system was its integration of a terrestrial laser scanner in $2 \mathrm{D}$ line mode, which is primary not intended for mobile applications. The complete calibration procedures of a combined group of connected sensors, especially the angular misalignment between the inertial measurement unit and laser scanners coordinate axes (boresight alignment; processed in software RiPROCESS, Riegl), have been accomplished and evaluated in terms of absolute and relative accuracy. This material is available for students to study this topic. In addition, visits with groups of students are organized in the company where this mobile system and real projects are demonstrated.

\subsection{Satellite Remote Sensing}

With the availability of high and very high resolution satellite images (the first IKONOS in 1999) the processing and use of satellite remote sensing images approached to photogrammetric methods of georeferencing and data compilation. Pixel oriented classification method that dominated for medium spatial resolution images is for high and very high resolution satellite images replaced by object oriented methods. On the other hand, in the scope of the Copernicus programme that is coordinated and managed by the European Commission, data for monitoring the Earth is collected through the Sentinel satellites and the contributing missions. Many value-added services can be tailored to specific public or commercial needs, resulting in new business opportunities, as this data is free to use. For students it is very important to have this information as this can motivate them for innovation and business ideas in their later professional career.

The Sentinels imagery can be downloaded from Copernicus's and ESA's Sentinels Scientific Data Hub, however the download of the data can be quite time-consuming. We thus use the application developed by Slovenian IT company Sinergise (http://www.sinergise.com/en) which is focused on the development of large-scale GIS applications. Through their Sentinel Hub (http://www.sentinel-hub.com/) and their application Geopedia one can easily access the Sentinel-2 imagery, and even more, Geopedia provides links to single tiles and bands, including metadata. Using Geopedia one can quickly obtain, for example, all the Sentinel's-2 multispectral bands in $10 \mathrm{~m}$ resolution (Figure 10).

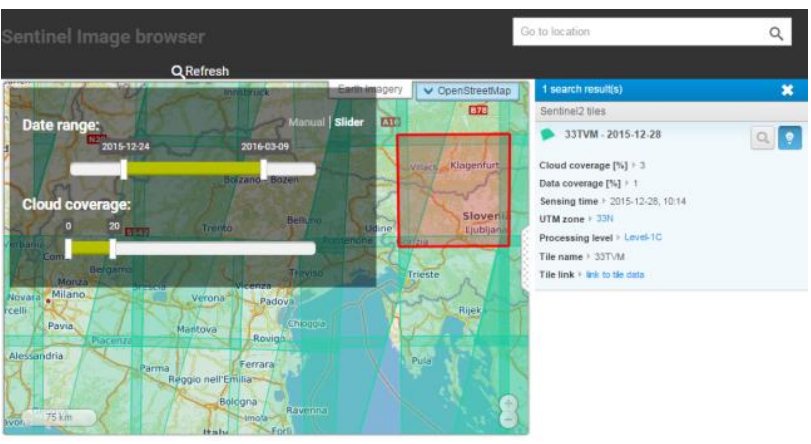

Figure 10: Sentinel Hub in Geopedia

For the pixel classification of satellite imagery, students perform exercises in ArcGIS. For the object oriented classification they use free software SPRING and INTERIMAGE, both of Brazil's National Institute for Space Research. Our plan for the near future is incorporating free and open source QGIS software and the Orfeo toolbox for the object oriented classification in students' exercises. 


\section{ACTIVE TEACHING METHODS AND APPROACHES TO LEARNING}

Active teaching methods are being widely promoted by the science of the didactic teaching, as being proved to better motivate students and increase their knowledge compared to the traditional way of teaching (Puklenk Levpušček et al., 2005). University teachers can use different methods of team work like: work in a pair, snow-ball method, buzzing groups, role playing, brain storming, case study, pro and contra debate, press conference etc. (Ramsden, 2003; Puklenk Levpušček et al., 2005). The most important is that methods are selected according to the goals of an activity and used in a proper way. The lecturer should take enough time for a good preparation of each activity.

Further on, in the educational psychology it has been recognized that there are different approaches to learning: deep, surface, strategic and apathetic (Entwistle et al, 2000). Deep learning approach means focusing on the meaning, connecting present knowledge with new information and knowledge from other subjects, connecting knowledge with everyday experience. It means also an active interaction through organizing the contents into reasonable units. Deep learning is driven by internal motivation, wish for knowledge and understanding. On the other hand surface learning means mostly memorizing without understanding. The new knowledge is not linked with the previously gained. Knowledge has no reflection and connection with the experience. Information is receiving in a passive way. Usually, tasks are seen as external burden. Surface learning is driven by external motivation, i.e. pressure from parents or society to get a specific educational degree, accompanied by the fear of failing. However, the deep and surface approaches to learning are not an isolated attributes of a learning person, as an individual can use both for different tasks. This means that according to specific situation one can select the approach following the interests, available time for the task etc. The combination of deep and surface learning approach is defined as strategic approach which is oriented to results and specific achievements. The extremity in the negative meaning is the apathetic learning approach which is shown as the complete absence of interest, motivation and sense of purpose for study. As this state of a person can have a more serious psychological background, we are not considering this in our paper.

With understanding that students can have different approaches to learning, the best teaching results could be achieved by adapting the teaching methods to the type of learning approach in a group or a class. In the practice this would mean that if we have a class of highly motivated students that use strategic approach to learning, we should take this into the account when preparing our lectures. Of course, there are usually students in a class with a mix of learning approaches, but some of the approaches may be prevailing. To find out which approach to learning is dominating in a group of students, we can use an appointed questionnaire known as Approaches to Studying Inventory (ASI), which has been developed by educational psychologist Noel Entwistle in 1981, with later revision known as Approaches and Study Skills Inventory for Students (ASSIST) (Entwistle et al, 2000). This questionnaire is composed of 30 statements that the inquired person ranks in the scale of five grades $(0,1,2,3,4)$, according to individual conformance to the particular statement. Each statement is further connected to a factor group (all together 7 factor groups: $\mathrm{A}, \mathrm{B}, \mathrm{C}, \mathrm{D}, \mathrm{E}, \mathrm{F}, \mathrm{G})$, that enable to assess the approaches to learning and predict the overall study success of the inquired person (student). The results are gained by summing up all the scores by factor groups. The meaning of a particular factor group is explained in Table 2. The factor groups $\mathrm{A}, \mathrm{D}, \mathrm{D}+\mathrm{C}+\mathrm{E}$ are indicating the deep learning approach, the factor groups $\mathrm{B}$, $\mathrm{E}+\mathrm{F}, \mathrm{B}+\mathrm{F}+\mathrm{G}$ are indicating surface learning approach.

\section{IMPLEMENTATION OF ACTIVE TEACHING METHODS}

\subsection{Examples of Lectures in a Class}

The implementation of some active teaching methods were tested in the spring semester of academic year 2014/2015 in the class of the first year students of the MA-GG, in the course of the subject Remote Sensing and Photogrammetry 2. In the previous academic years we used mainly traditional methods of teaching with some additional seminar work of students where they presented their results in the class in a form of slide presentations. Below we present some selected concrete examples on active teaching methods we used in the mentioned class.

\section{Pro et contra debate}

In lectures students learn the theory on different advanced methods of aerial triangulation (AT): automated AT, GNSS supported AT, integrated sensor orientation, as well as the principles of direct sensors orientation. Traditionally, the lecturer will give at the end the comparison of the methods in a form of a table. To attract more attention from students, we decided to use the method called pro et contra debate. We selected two students and gave them the instruction that one of them is arguing strongly for traditional methods of aerial triangulation and the other for advanced methods. We additionally appointed three students to each of the debater, who are helping them during the debate with further hints and arguments they write to a piece of paper and hand it over to the debater. Another two students are selected, each writing on the blackboard the key words of the arguments. All other students are listening to the debate. The debate took approximately 10 minutes of time, but at the end the students came alone to almost the same conclusions that would be otherwise just presented from the teacher.

\section{Buzzing groups}

This method is very useful also in large groups of students. We give them a task and they discuss in smaller groups (e.g. four students in a group), so that they can stay at their seats. We implemented this method in the topic of planning photogrammetric project. First, we introduced the objectives of a project. An investor is asking for a bid from a company for a specific product (e.g. topographic map of a public garden), but is open for negotiation. The task for students is to collect ideas for the realization of the project, where they should take into account different methods of remote sensing and photogrammetry as well as costs of the project. The teacher is playing a role of the investor and gives them additional information if they have questions. Than students have a limited time (15-20 minutes) for the discussion in groups and after that each group presents the outline of the offer which is than discussed with the teacher and the students in the class. Students are stimulated to think about pros and cons of particular technologies, costs of the work, possibilities of augmented products, for example not only to produce a topographic map but organize data as topographic information 
system with additional attributes, produce digital elevation model and orthophoto (e.g. when using UAS as the surveying method), prepare a 3D animation for promotional purposes, etc.

\section{Press conference}

After presenting the general state-of-the-art of satellite systems for Earth observation by the teacher, an overview of the available satellite systems is given. This can be quite boring for students if it is presented in a form of tables and pure technical information. Thus, a few students are asked in advance to search for information (each student for one satellite system, e.g. Copernicus programme and Sentinel satellites, Landsat programme, satellites from Digital Globe etc.). Usually, they will give a presentation in slides. To make these presentations more active, we decided for the method called press conference. Like in a real press conference, presenting students are giving short and extracted information and other students (the audience) are than asking them like journalists. The presenters than give more detailed explanations and answers to the questions. The questions from the audience may be also provoking (Do you think that imagery from this satellite system is competitive with the other systems?). Students had a lot of fun in this lesson and they also memorized much more information on the satellite systems as if just presented by the teacher.

\section{Moderated discussion}

Quality assurance and quality control in photogrammetric projects is one of the very important topics in this subject. The theory on this may be for the students quite difficult to understand. As a practical example of using the quality concepts in the practical project, we selected the Guidelines for Best Practice and Quality Checking of Ortho Imagery (Kapnias et al., 2008). In previous years the teacher asked student that they read this document of their own and then there was a discussion in a class. The result was that not all students have read the document and also the discussion did not develop. The active teaching approach was realized only in a slightly different way. The students were asked in the same way to read the document, but a few students were additionally asked to prepare questions, extract main statements, connect the contents of the document with the presented theory in the lectures etc. Then these students moderated the discussion in the class, teacher being only a passive participant and giving additional explanation if being asked. The result was astonishing, all the students have read the document and the discussion was vivid and fruitful.

These, although just a few examples show that implementation of active teaching methods do not demand very sophisticated teaching tools. Sometimes being very simple, but effective, these methods can bring additional "kick" into the lectures. However, the lecturer must think about which method to use in particular topic, and also not too many activities should be used at a time.

\subsection{Evaluation of Active Methods}

Before the end of the spring semester and after using some new teaching methods in the class, the students were asked to answer two types of a questionnaire (22 students took part in the inquiry that were present in lectures at that day). First was the standard questionnaire by Noel Entwistle, as described in Chapter 4 of this paper, however the translated version in Slovene language (adopted from Puklek Levpušček et al., 2005). We developed the second questionnaire for our purpose to get the feedback from students on more active teaching and learning methods.

The students were asked to answer the both questionnaires one after another, in an anonymous way.

\begin{tabular}{|c|c|c|c|c|c|}
\hline $\begin{array}{l}\text { Factor } \\
\text { group }\end{array}$ & $\begin{array}{l}\text { Meaning of } \\
\text { factor group }\end{array}$ & $\begin{array}{l}\text { Max. } \\
\text { possible } \\
\text { score }\end{array}$ & Min. & Max. & Average \\
\hline $\bar{A}$ & $\begin{array}{l}\text { Orientation to } \\
\text { achievements }\end{array}$ & 24 & 5 & 18 & 13 \\
\hline $\mathrm{B}$ & $\begin{array}{l}\text { Orientation to } \\
\text { reproduction }\end{array}$ & 24 & 6 & 20 & 14 \\
\hline $\mathrm{D}$ & $\begin{array}{l}\text { Oriention to sense } \\
\text { and meaning }\end{array}$ & 24 & 9 & 20 & 14 \\
\hline $\mathrm{C}+\mathrm{G}$ & Strategic approach & 24 & 6 & 19 & 14 \\
\hline $\mathrm{E}+\mathrm{F}$ & $\begin{array}{l}\text { Serial and partial } \\
\text { learning }\end{array}$ & 24 & 5 & 18 & 11 \\
\hline $\mathrm{D}+\mathrm{C}+\mathrm{E}$ & Elastic approach & 48 & 18 & 39 & 30 \\
\hline $\mathrm{B}+\mathrm{F}+\mathrm{G}$ & $\begin{array}{l}\text { Symptoms of } \\
\text { disadvantageous } \\
\text { study success }\end{array}$ & 48 & 15 & 30 & 24 \\
\hline $\begin{array}{l}-------- \\
----\end{array}$ & ------------------- & --------- & $\begin{array}{c}----- \\
-- \\
\end{array}$ & $\begin{array}{l}----- \\
\end{array}$ & ----------- \\
\hline $\begin{array}{l}\mathrm{A}+\mathrm{C}+\mathrm{D} \\
+\mathrm{E}+(48- \\
\mathrm{B}-\mathrm{F}-\mathrm{G})\end{array}$ & $\begin{array}{l}\text { Prediction of study } \\
\text { success }\end{array}$ & 120 & 48 & 86 & 68 \\
\hline
\end{tabular}

Table 2: The results of the inquiry

The results presented in Table 2 show that neither of the approaches to learning is predominant (average score of groups $\mathrm{A}, \mathrm{B}, \mathrm{D}, \mathrm{C}+\mathrm{G}, \mathrm{E}+\mathrm{F}$ are between 11 and 14 , this is $46 \%-58 \%$ of the maximum possible score). A slightly higher score is for elastic approach (62\% of the maximum possible score). We can ascertain that the students in this class are middle-range motivated and also the prediction of the study success is just slightly over the average possible score.

In the second questionnaire we wanted to find out what students think about more active teaching methods. We presumed that students with more expressed deep approach to learning are in more favour to active teaching methods that students with surface approach to learning. The questionnaire is composed of 14 questions, 12 of them are to rank in the same manner as in the Entwistle questionnaire, in the two last questions the students can write down their own opinions (on personal obstacles for more active cooperation and which methods they liked the most). We are not going into details of this questionnaire as we would just like to present the final outcomes. To our surprise, we did not confirm our presumption as the answers were in around 70-95\% in favour to active teaching approach with no clear correlation to the approach to learning. Our subjective explanation to these results is that students were in general satisfied with implementation of new methods and due to the lack of other experiences they could not develop critical judgement.

In the written opinions about personal obstacles for more active cooperation students exposed personal characteristics as not enough self-confidence, reservation, introversion, fear etc. This is good to know for a teacher as one can use methods where an individual student is not exposed, e.g. work and discussions in small groups. The students expressed the best favour to practical examples and invited lectures from practice. One of the answers on active teaching methods was: "Different and more active approaches, cooperation of students and teacher in the course of lectures, all these variegate the atmosphere in the class, improve concentration and interest for the topics." To our opinion, this is the essence of more active teaching methods - to 
create a stimulating atmosphere in the class and to gain the attention and interest from students.

\section{CONCLUSIONS}

Fast technological changes and development require steady improvements in university study programmes. However, only changes in curriculum are not enough as there are more and more new topics while the time for lectures and practical exercises remains limited. The solution may be in applying more active teaching methods and to generalize theoretical concepts where possible. In this paper we presented our recent approaches and experience to this challenging issue. Although we tested some of active teaching methods in only one class of master students, the results are encouraging. Active teaching methods increase interest of students during the lectures, improve understanding and knowledge, and finally result in better grades in exams.

Further on we would like to emphasise that cooperation of university and private companies is essential not only for research and development, but also for educational purposes. Some of private companies in Slovenia have specific equipment and computer programs that our faculty cannot afford to buy. Through good cooperation with these companies we arrange that students can use data and equipment for master theses, case studies, project work etc.

Occasional invited lectures of colleagues from the practice fresh up some topics. Of course, such invited lectures must be well selected and prepared in cooperation of the teacher and invited professional. Some students later asked at companies for work during the summer holidays, some also get employed after finishing the study or even establish their own company.

We hope that our experiences and presented examples in this paper are inspiring. However, we are aware that there are still many possible improvements either in teaching methods or practical exercises.

\section{REFERENCES}

Al-Tahrir, R., 2015. Integrating UAV into geometics curriculum. The International Archives of the Photogrammetry, Remote Sensing and Spatial Information Sciences, Toronto, Canada, Vol. XL-1/W4, pp. 387-390.

Balek, V. (2013) Development of a computer program for computation of orientation of a stereo pair: graduation thesis. University of Ljubljana.

Chen, J., et al., 2015. Information from imagery: ISPRS science vision and research agenda. ISPRS Journal of Photogrammetry and Remote Sensing.

http://dx.doi.org/10.1016/j.isprsjprs.2015.09.008

Entwistle, N., Tait, H., McCune, V., 2000. Patterns of response to an approaches to studying inventory across contrasting groups and contexts. European Journal of Psychology of Education, 15(1), pp. 33-48.

Grigillo, D., Kosmatin Fras, M. Petrovič, D., 2011. Automatic extraction and building change detection from digital surface model and multispecrtral orthophoto. Geodetski vestnik, 55(1), pp. 28-45.

Kai-Wei, C., Meng-Lun, T., Chien-Hsun, C., 2012. The

Development of an UAV Borne Direct Georeferenced

Photogrammetric Platform for Ground Control Point Free Applications. Sensors 2012, 12(7), pp.9161-9180.

Kapnias, D., Milenov, P., Kay, S., 2008. Guidelines for Best Practice and Quality Checking of Ortho Imagery, Issue 3.0. European Commission, Joint Research Centre.

Koler-Povh, T., Mikoš, M., Turk, G. 2014. Institutional repository as an important part of scholarly communication. Library Hi Tech, 32, 3, pp. $423-434$.

http://dx.doi.org/10.1108/LHT-10-2013-0146

Kosmatin Fras, M., Valič, R., Bone, M., Mesarič, M., 2015. The use of small unmanned vehiclesfor spatial data acquisition. Land surveying (r)evolution : proceedings of the 43rd Slovenian Surveying Day. Ljubljana; pp.67-77

Kumar, S., 2013. Realization and calibration of a mobile laser system : graduation thesis. University of Ljubljana.

Peterman,V., 2015. Landslide activity monitoring with the help of unmanned aerial vehicle. The International Archives of the Photogrammetry, Remote Sensing and Spatial Information Sciences, Toronto, Canada, Vol. XL-1/W4, pp. 215-218.

Petrovič, D., Drobne, S., Stopar, B., 2008. Harmonization of education programmes on geodesy - new study programmes. Geodetski vestnik, 52( 4), pp. 639-652.

Puklenk Levpušček, M., Marentič Požarnik, B., 2005. Skupinsko delo za aktiven študij (Team work for active study). University of Ljubljana, Faculty of Arts.

Ramsden, P., 2003. Learning to teach in higher education. $2^{\text {nd }}$ Edition. London: RoutledgeFalmer.

Triglav, M., Bric, V., 2015. The project of laser scanning of Slovenia is completed. Geodetski vestnik, 59(3), pp. 586-592. 